\title{
Characterizing shifting pattern of disaster-induced death and disaster management policies: a regional analysis from Odisha, India
}

\author{
Manoranjan Mishra ${ }^{1}$, Tamoghna Acharyya ${ }^{2, *}$ and Namita Pattnaik ${ }^{3}$ \\ ${ }^{1}$ Department of Natural Resource Management and Geoinformatics, Khallikote University, Berhampur 761008 , India \\ ${ }^{2}$ School of Sustainability, Xavier University, Bhubaneswar, Plot No. 12(A), Harirajpur 752 050, India \\ ${ }^{3}$ Department of Geography, Government College (Autonomous), Angul 759 143, India
}

\begin{abstract}
A study was conducted to understand if the disaster death in Odisha, India across five categories, viz. tropical cyclone, lightning, heat wave, cold wave and extreme precipitation events underwent any significant change during 2001-14. It was based on timeseries data available at the National Data Portal of India. Results of the study suggest that the number of fatalities from sporadic meso-scale meteorological hazards like cyclones and heavy precipitation have drastically reduced due to better forecasting and effective evacuation strategies adopted by the Government. However, fatalities due to more frequent recurring extreme events, such as lightning and heat stress are on the rise. Male adults and middle-aged people (30-44 and $45-59$ years respectively) constituted the most vulnerable groups affected by lightning and heat stress which account for maximum number of deaths in the state. Older population (especially older women) were more vulnerable towards cold wave due to reduced thermoregulatory mechanism. The finding is significant, because often deaths due to lightning injury, heat stress and cold wave either go unnoticed or are under-reported. We expect that the present study which focuses on gender and age disaggregated death would help in adopting more targeted mitigation or adaptation strategies in Odisha. The study also points out the need of a single and detailed spatio-temporal data infrastructure for all kinds of disaster deaths for more in-depth and insightful analysis.
\end{abstract}

Keywords: Disaster-induced death, mitigation strategies, regional analysis, shifting patterns.

EXTREME hydroclimatic natural hazards such as flash floods, storm surges, heat waves, cold waves, droughts and cyclones are the leading cause of exponential rise in human fatalities and property loss ${ }^{1}$. Direct economic loss of US\$ 2.4 trillion (in 2012 prices) and around 1.94

*For correspondence. (e-mail: acharyyat@xsos.edu.in) million deaths occurred globally due to climate-induced natural disasters between 1970 and 2012 (ref. 2). While on the one hand these rising losses may be attributed to the exponential increase in population in vulnerable regions and better recording of disaster impacts ${ }^{3,4}$, there is growing scientific evidence that anthropogenic climate change is the critical driver for such losses ${ }^{5-7}$. This paradigm shift in climate-related disaster deaths and loss of property around the world warrants intervention in the disaster management framework and adaptation of policies, more so in developing countries.

The most significant impact of extreme hydro-climatic events is premature deaths due to natural disasters ${ }^{8}$. Premature human fatalities have varying degrees of ramification at the family level and on demographic dividends at the national level. Premature deaths bring mental agony to the family members. If the family loses the only income-earning individual, then the household will be trapped in a vicious circle of poverty ${ }^{2}$. Thus, premature death of the working population group due to climateinduced disasters has not only significant consequences on demographic structure, but also affects the economic development of a country ${ }^{9,10}$. According to Neumayer and Plümper ${ }^{11}$, premature deaths due to natural disasters lower the life expectancy of women compared to men. Female disaster death rates are more in the developing countries than in the developed world ${ }^{12}$. Climate-induced natural deaths will likely show an increasing trend, as more people will be bracketed in the exposure group in the coming days.

Odisha lying on the east coast of India is known as the 'disaster capital' of the country ${ }^{13}$. The poverty-ridden state experiences multiple disasters, such as severe cyclonic storms, floods, heat waves and extreme precipitation events ${ }^{14,15}$ leading to deaths and economic losses ${ }^{16}$. Though the Odisha coast constitutes $17 \%$ of the east coast of India, approximately $35 \%$ of cyclonic storms originating in the Bay of Bengal make their landfall in this segment bringing in causalities and devastation. The super cyclone of 1999 was responsible for more than 10,000 
Table 1. Disaster deaths in Odisha, India from 2001 to 2014

\begin{tabular}{|c|c|c|c|c|c|c|}
\hline Disaster category/year & Cold wave & Lightning & Tropical cyclone & Heat wave & Extreme precipitation & Grand total \\
\hline 2001 & 6 & 226 & 6 & 61 & 26 & $325[9]$ \\
\hline 2002 & 3 & 207 & 2 & 78 & 11 & $301[8]$ \\
\hline 2003 & 5 & 228 & 1 & 98 & 50 & $382[10]$ \\
\hline 2004 & 2 & 260 & 1 & 76 & 74 & $413[11]$ \\
\hline 2005 & 7 & 243 & 0 & 94 & 9 & $353[9]$ \\
\hline 2006 & 2 & 254 & 0 & 52 & 24 & $332[8]$ \\
\hline 2007 & 5 & 362 & 0 & 55 & 18 & $440[11]$ \\
\hline 2008 & 2 & 369 & 5 & 69 & 9 & $454[11]$ \\
\hline 2009 & 17 & 244 & 17 & 101 & 20 & $399[10]$ \\
\hline 2010 & 54 & 318 & 0 & 130 & 24 & $526[13]$ \\
\hline 2011 & 2 & 329 & 0 & 51 & 21 & $403[10]$ \\
\hline 2012 & 3 & 250 & 0 & 124 & 19 & $396[9]$ \\
\hline 2013 & 1 & 270 & 1 & 101 & 42 & $415[10]$ \\
\hline 2014 & 4 & 289 & 0 & 78 & 5 & $376[9]$ \\
\hline Grand total (\%) & $113(2)$ & $3849(70)$ & $33(1)$ & $1168(21)$ & $352(6)$ & $5515(100)$ \\
\hline Average death per year & 8 & 275 & 2 & 83 & 25 & 394 \\
\hline
\end{tabular}

Percentage deaths for lightning, heat wave and extreme precipitation events are shown in parentheses, while deaths per million population are shown in square brackets.

premature deaths in Odisha ${ }^{17}$. Recently (May 2019), extremely severe cyclonic storm 'Fani' ravaged the state taking away 64 human lives, besides causing severe damage to the extent of INR 24,176 crores $^{18}$. The state also experiences periodic floods from a complex of ten major river systems ${ }^{15}$. Drought is a recurring problem in western Odisha, the frequency and intensity of which is on the rise ${ }^{15}$. The state is also prone to heat wave ${ }^{19}$ and lightning $^{20}$ that cause deaths at a more constant rate throughout the year. Disaster-related research, especially studies on disaster-induced fatalities in Odisha are descriptive $^{20}$, and restricted to a specific year and geographical area ${ }^{17,19,21}$. Long-term fatality trend analysis studies are lacking. The present study fills this knowledge gap by evaluating the trend and pattern of fatalities induced by hydro-metrological/climatic disasters in Odisha on various age groups of both sexes for the period 2001-14 using data stored in the National Data Portal.

\section{Data and methods}

We downloaded data from https://data.gov.in/catalog/ stateut-wise-distribution-accidental-deaths-un-natural-causes. Three CSV (comma separated values) files were available for download: (1) the data file 2001-2012; (2) data file 2013 and (3) data file 2014. Each CSV file had 16 fields with state/Union Territory (UT), year, cause, age bracketwise fatalities for male and female $(\leq 14,15-29,30-44$, 45-59 and $\geq 60$ years). State-wise census data (downloaded from http://censusindia.gov.in) were available for 2001 and 2011; the population for the interim years (i.e. 2002-10 and 2012-14) was projected by the published average annual exponential growth rate. All disasters were reduced to the following five categories to make them feasible for comparison with previous studies in India ${ }^{2}$ :

Category 1: Cold wave (clubbing together fatalities from avalanche and exposure to cold).

Category 2: Extreme precipitation (clubbing flood, landslide, torrential rainfall).

Category 3: Heat wave (clubbing forest fire, heatstroke, heat/sunstroke, starvation/thirst).

Category 4: Lightning.

Category 5: Tropical cyclone (clubbing cyclone/tornado, tornado).

The processed data had only six fields, namely state/UT, year, disaster category, gender $(\mathrm{M} / \mathrm{F})$, age bracket and number of deaths in the final dataset. Data were cleaned and processed by the power query and pivot table utilities of Microsoft Excel for Office 365.

\section{Results and analysis}

\section{Temporal variation of fatalities}

During the study period (2001-14), Odisha recorded a total of 5515 premature disaster deaths with an average death rate of 394 persons per annum (Table 1). After 2010, an overall decreasing trend in fatalities was noticed. Disaster death followed the pattern: lightning $(70.6 \%)>$ heat wave $(21.1 \%)>$ extreme precipitation $(6.4 \%)>$ cold wave $(2.0 \%)$. The least number of deaths (33) was due to tropical cyclone $(0.06 \%)$. Lightning and heat wave deaths registered an increasing trend (upper panel, Figure 1), while extreme precipitation exhibited decreasing trend over the years (lower panel, Figure 1). Cold wave and cyclone-induced fatalities remained low and nearly uniform (lower panel, Figure 1). 

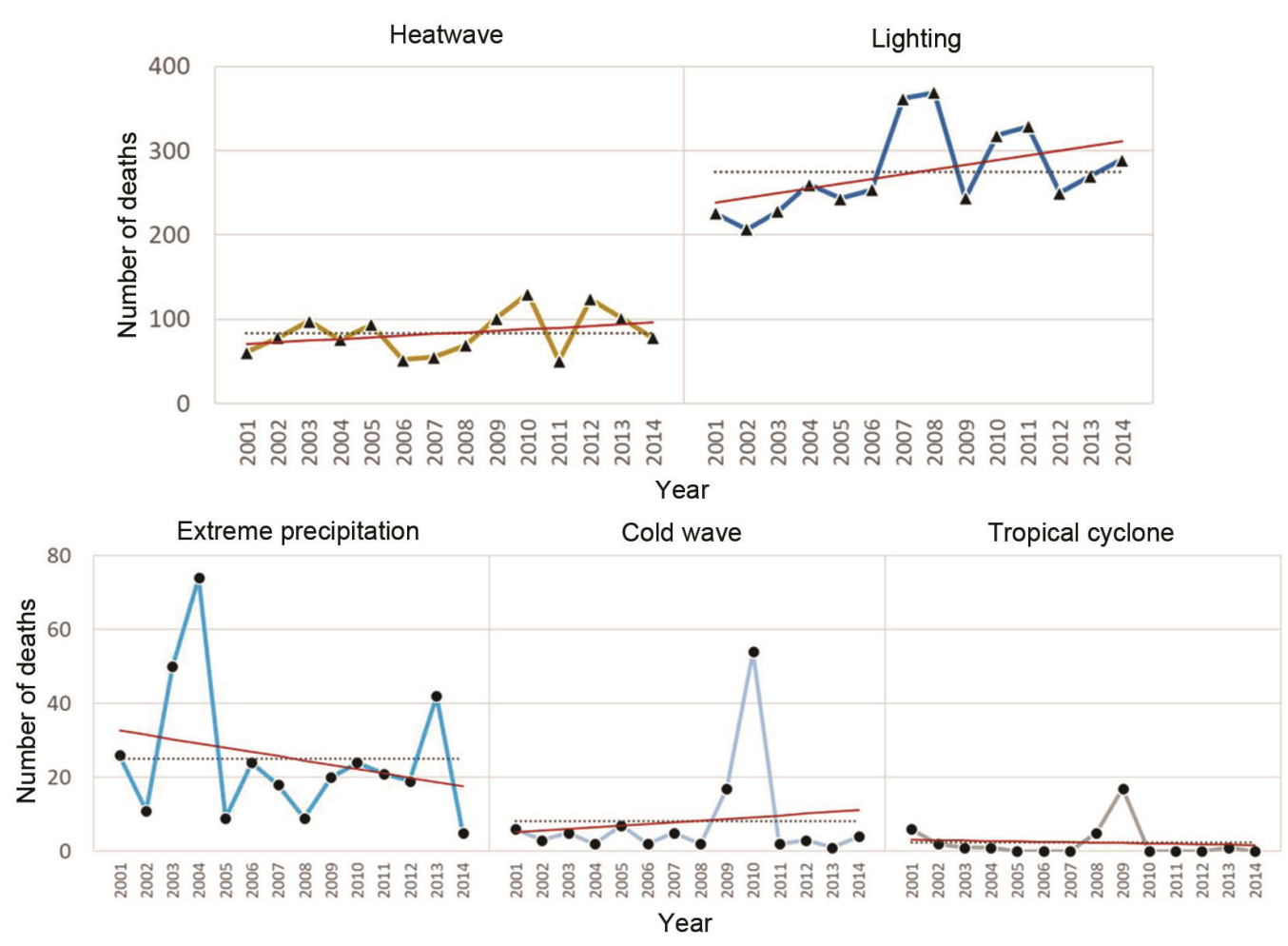

Figure 1. Time series of disaster fatalities over 2001-14. The upper panel of the chart depicts disasters causing more than 100 deaths per year, whereas the lower panel represents deaths less than 100 per year. Red line indicates the trend, while black dotted line indicates average fatality.

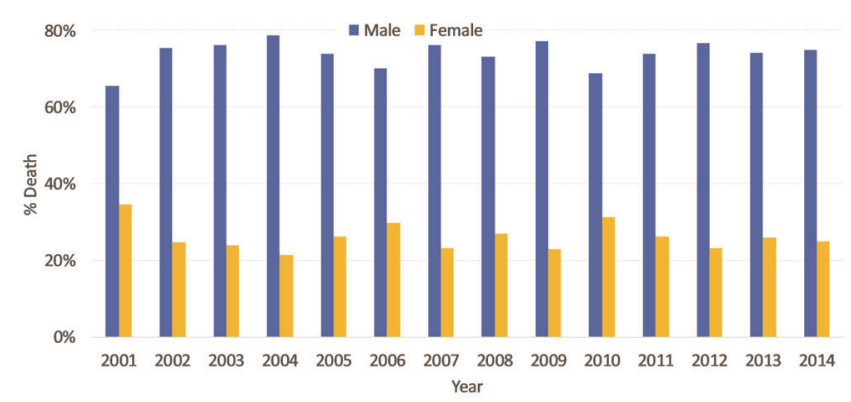

Figure 2. Percentage death of male and female across all disaster categories from 2001 to 2014.

Disasters like lightning, heat wave and extreme precipitation are more consistent in causing deaths every year in Odisha (Table 1). The share of lightning in annual disaster death ranged between $60 \%$ (2002) and $80.3 \%$ (2007). Whereas deaths due to heat wave varied from $12.5 \%$ (2007) to $26.6 \%$ (2005). The extreme precipitation caused an average of 25 annual deaths.

Deaths due to cold wave were a normal annual incident in the state, but the numbers were small. Deaths due to tropical cyclone were the lowest; on an average two per year (Table 1).

\section{Gender distribution of casualties}

The incidence of disaster deaths was on an average three times higher for males than females (Figure 2). Male deaths ranged between $65.5 \%$ and $78.7 \%$, whereas female deaths ranged between $21.3 \%$ and $34.5 \%$. An average of $74 \%$ of disaster deaths in the state was contributed by the male population.

\section{Age distribution of casualties}

Disaster deaths were reported across all age groups $(\leq 14$, $15-29,45-59$ and $\geq 60$ years) of both genders in the state. However, the magnitude of death was much higher in the age group between 15 and 59 years, the so-called working age population, compared to the old population (above 60 years) and children (below 14 years of age) (Figure 3). Working male population between 30 and 59 years of age accounted for nearly half of the total disaster deaths (2612 out of 5515) in Odisha. The second largest number of premature disaster deaths (829) occurred in the young working male group between 15 and 29 years of age. The death toll of females below 14 years was the lowest, a total 90 during the study period. Adults of both sexes in the age group of 30-44 years accounted for the highest number of deaths - at 1421 for male and 485 for female (Figure 3).

Frequency distribution of lightning fatalities was symmetrical in shape. Adult population (30-44 years) of both sexes registered highest number of deaths, while children ( $\leq 14$ years) and the elderly ( $>60$ years) accounted for less than $7 \%$ of total deaths (Figure 3 ). We also observed 

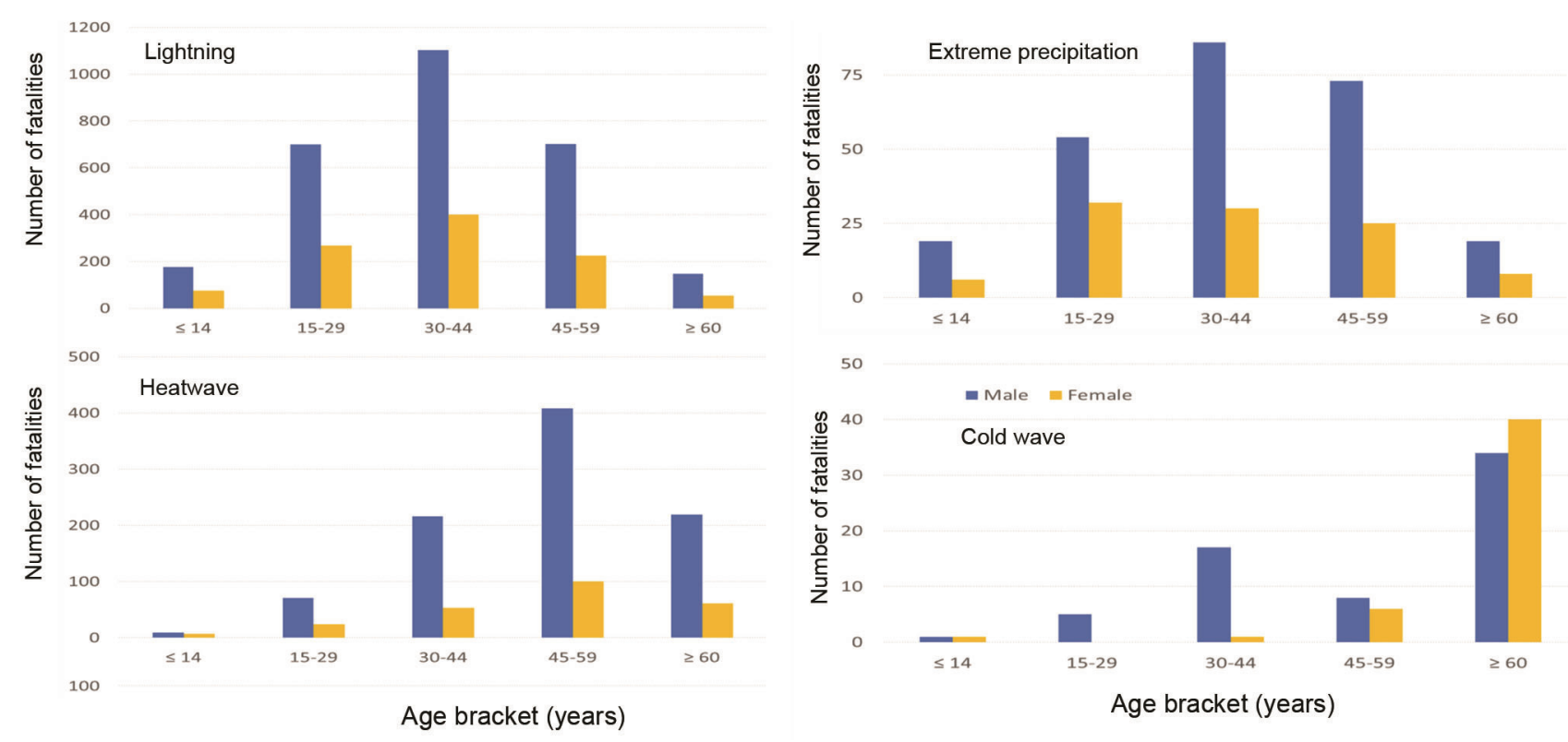

Figure 3. Frequency distribution of casualties across various age-brackets versus different categories of disasters. The gender disaggregated frequency distribution has not been shown for cyclones due to small sample size $(n=33)$ and sporadic nature of the disaster.

similar symmetrical distribution pattern in case of deaths due to extreme precipitation. By contrast, heat wave and cold wave death frequency showed asymmetric distribution. For example deaths due to cold wave, tailed towards the left (negative skew), depicting that the largest death share belongs to the elderly population $(\geq 60)$; it was notably higher in the case of older females (Figure 3 ).

A considerable share of lightning deaths occurred in the young adult group between 15 and 29 years of age and the working group between 30 and 44 years of age (Figure 3). In contrast, deaths due to heat wave were strikingly high in middle-aged people (45-59 years), especially among the male. Death toll in the elderly group ( $\geq 60$ years) was the second highest. In the young adult population (15-29 age group), heat wave-related deaths decreased to 95 . Children below 14 years were less affected by heat wave (Figure 3 ).

Extreme precipitation-related casualties were 251 for male and 101 for female. The death toll due to extreme precipitation was the highest among the young adults (30-44 years), followed by middle-aged people (45-59 years). The elderly ( $\geq 60$ years) and children ( $\leq 14$ years) showed the lowest number of deaths.

\section{Discussion}

\section{Paradigm shift in the trend of disaster deaths in Odisha}

Odisha is known for its extreme disaster events like cyclones and floods, leading to periodic loss of life and property $^{22-24}$. For example, the 1999 super cyclone took away 10,000 human lives in the state, which is almost double of the total casualties reported (5515) in the present study period (2001-14). This disproportionate number of deaths in 1999, being an outlier, inflates the average death toll giving rise to the widespread perception, that cyclones and floods are major killers in Odisha $^{20}$. However, the present study highlights that there has been a paradigm shift in disaster deaths in the state during the last 14 years between 2001 and 2014, when deaths due to cyclonic and extreme precipitation events were majorly replaced by those due to lightning strikes $(69.7 \%)$ and heat stress $(21.2 \%)$. The drastic reduction of cyclonic and flood-related deaths has been attributed to the State Government's proactive steps in issuing early warning, forcing evacuation and effective disaster risk management strategies ${ }^{20,22,23}$ led by the Odisha State Disaster Management Authority (OSDMA), which was established in the aftermath of the super cyclone of 1999. The 'zero-casualty' approach opted and implemented by the State Government by evacuating lakhs of people to safer places during cyclone Phailin in 2013 and cyclone Fani in 2019 has been appreciated by the United Nations. While this is commendable, it must be mentioned that deaths due to lightning and heatstroke often go unnoticed by the media and policymakers, although they constitute more than $90 \%$ of fatalities as shown in the present study between 2001 and 2014. This may be so because these deaths are isolated and sporadic. However, annual average fatalities due to lightning and heat wave in Odisha are greater than the global and national average $e^{2,25,26}$. Policymakers should perceive the change in death patterns due to natural causes as seen between 2001 and 
2014 in this study. To reduce the death toll, advanced early warning system, proactive policy and planning should be in place ${ }^{20}$.

\section{Gender disparity in disaster deaths}

Another insight from this study is that the male population is more vulnerable to disaster deaths than the female population in Odisha across all age groups and disaster categories. The exception is death due to cold wave which is more in the elderly population ( $>60$ years). The gender disparity of disaster deaths in this study contradicts the traditional theory of biological and physiological differences of the male and female population, where it has been postulated that the male is stronger than the female to resist the impact of disaster ${ }^{11,27,28}$. This result is contrary to the traditional theories of 1980 s and 1990 s that more female deaths are observed than male, nationally and globally ${ }^{9,20}$, and especially in the developing countries than in developed countries ${ }^{11,20,29}$. The socio-cultural norms of Odisha might play a pivotal role in disproportionate disaster deaths among males. The poverty-ridden state and patriarchal division of labour in an agro-based economy, expose more men (often the sole bread-winners in a family) in the age group of 15-29, 30-44 and 45-59 years to work in the open fields than women ${ }^{20}$, making them physically more vulnerable to the extreme weather events $^{30-32}$. Therefore, disaster preparedness should shift its approach from gender neutrality to greater emphasis towards male working-class age bracket of 15-59 years, specifically youngsters between 15 and 29 years. Young adults (30-44 years) should be given importance for protection from lightning strikes and extreme precipitation. Middle-aged men (45-59 years) and the elderly ( $\geq 60$ years) should be given importance for protection from heat wave. The older population, especially women, would need protection from cold wave.

\section{Lightning-related deaths}

This study highlights that the largest share of disaster deaths recorded in Odisha during the study period is due to lightning with an average annual death toll of 275 persons. It is lower than the national average (2234 persons per year), but higher than in most of the developed countries like USA (30 people per year) ${ }^{33}$. With 9 lakh strikes, Odisha alone accounted for $15 \%$ of the total lightning strikes in India between 1 April and 31 July 2019 (ref. 34). The districts of Mayurbhanj, Dhenkanal, Ganjam and Sundargarh reported majority of lightning fatalities (https:// www.downtoearth.org.in/news/lightning-claims-more-livesin-odisha-than-any-other-calamity-42218). The northwestern tribal districts of Odisha are the hotbed zones of lightning events possibly due to co-occurrence of convective available potential energy (CAPE), optimum aerosol concentration, outgoing longwave radiation (OLR), surface temperature and electrical properties of the resulting cloud systems. About $88 \%$ of the total lightning strikes occur during the pre-monsoon and monsoon periods (March to September), and the rest 12\% during the postmonsoon period (November to February) ${ }^{35}$. Also $85 \%$ of lightning-related fatalities occur between May and September. Farmers working in the agricultural fields during the monsoon season are the main victims of lightning deaths in India as they get exposed to touch voltage, direct hit and step voltage-induced fatalities ${ }^{33}$. Given the fact that most lightning-related fatalities have specific spatial locations (open agricultural fields) and activities (farming), it provides an opportunity for strategic mitigation measures. Lightning fatalities can be prevented by educating the farmers and other stakeholders who work in open spaces on the 'do's' and 'don'ts' of taking shelter during a lightning. If there is no nearby building/shelter, farmers are advised to keep their feet as close as possible and crouch down ${ }^{33}$.

According to the recent data released by the Office of the SRC (Special Relief Commissioner), Odisha has registered a $31 \%$ decline in human casualties during 2018 19 (320 deaths) compared to 465 in 2017-18, 401 during 2015-16 and 400 during 2016-17 (ref. 36). Taking note of the fact that lightning fatality occurs due to the absence of forecast or warning systems, the SRC Office and OSDMA have initiated new measures such as early warning communication system (EWCS), wherein SMS alerts are sent to people about impending lightning hazard and safety measures, launch of system for accessing, tracking and alerting disaster risk information based on dynamic risk knowledge (SATARK) app and installation of 'outdoor alerting system' which blows a siren before the approach of any lightning in the 14 most vulnerable blocks of Odisha where the event is common. Lightning protection devices such as arresters and conductors have been installed in 879 cyclone shelters and other vulnerable buildings, which has prevented casualties during cyclones such as $\mathrm{Fani}^{37}$, with which about 100,000 lightning strikes were associated. Lightning Resilient India Campaign (LRIC) has also advocated the installation of locally made lightning protection arresters (LPAs) in schools, hospitals, homes and other buildings. Knowledge about lightning safety is being spread in schools, colleges and universities $^{37}$. The State Forest and Environment Department plans to plant palm trees which are good conductors of electricity due their height along the highways and in common land ${ }^{38}$.

\section{Heat wave and other death categories}

In Odisha, death related to heat waves constituting $21.16 \%$ of the total fatalities is the next significant killer. The state faces extreme heat waves during each summer 
season $^{36,39}$. In 1998, it witnessed a massive 2042 deaths due to heat wave ${ }^{19}$. Empirical studies show that around the world, heat waves cause more deaths than cold waves $^{20,40}$ due to increased risk of cardiovascular, cerebrovascular attack and dehydration ${ }^{41,42}$. Middle-aged male working population of Odisha (45-59 years) show disproportionately high level of fatalities due to heat waves as they are exposed to heat over extended periods compared to females ${ }^{43}$. In 2003, the Government of Odisha started heat wave management plans like awareness campaigns and 'do's' and 'don'ts' during a heat wave $^{19}$. These include avoiding going out in the sun when it is most intense (12:00 noon to $3: 00 \mathrm{pm})$, avoiding high-energy activities and wearing light-weight, lightcoloured, loose cotton clothes (https://www.osdma.org/ wp-content/uploads/2019/08/Heat-Wave.jpg). Repeated campaigning in the media (newspapers, radio and television) has proved to be useful, bringing about behavioural changes during the days of heat waves ${ }^{19}$. However, one needs to be cautious as more frequent spells of heat wave are predicted to hit the state in the coming years due to climate change ${ }^{44}$. Thus, improved forecasting, mitigation, and adaptation strategies are needed.

The third significant killer is extreme precipitation which accounts for $6.38 \%$ of total disaster deaths in Odisha. The number of deaths related to heavy precipitation and floods has decreased over time due to better forecast by the Indian Metrological and State Meteorological Departments, and timely dissemination of impending danger for effective evacuation and relief ${ }^{2,26}$.

\section{Moving forward}

The existing dataset lacks spatial and temporal information of the reported fatalities preventing more in-depth studies. Under-reporting of fatalities is common for disasters which are isolated and sporadic in nature, like lightning for example ${ }^{45}$. The available data further fail to differentiate between primary and secondary deaths. Primary deaths or deaths directly related to disasters are reported widely, but indirect or secondary deaths are not recorded, because deaths due to injury or morbidity arising from a natural cause take longer time ${ }^{32}$. The other concern is that disaster deaths must be recorded and verified within $24 \mathrm{~h}$. However, the whole processes requires more time.

Further, filtering of the disaster death data according to class, caste and gender is done at the block and district levels ${ }^{20}$; no proper protocol for data quality control exists. There is no uniform protocol for data collection and record-keeping practices related to disaster deaths, which impedes robust analysis and prediction. Thus, we strongly recommend a uniform disaster death data collection protocol (following the Sendai framework, for example) which will eventually save time and money, as well pre- vent duplication or replication of the disaster death records.

1. CRED, Natural Disasters 2017, Centre for Research on the Epidemiology of Disasters, Brussels, Belgium, 2017; https:// cred.be/sites/default/files/adsr_2017.pdf

2. Mahapatra, B., Walia, M. and Saggurti, N., Extreme weather events induced deaths in India 2001-2014: trends and differentials by region, sex and age group. Weather Climate Extrem., 2018, 21, $110-116$.

3. Ikefuji, M. and Horii, R., Natural disasters in a two-sector model of endogenous growth. J. Public Econ., 2012, 96, 784-796.

4. Paprotny, D., Sebastian, A., Morales-Nápoles, O. and Jonkman, S. N., Trends in flood losses in Europe over the past 150 years. Nature Commun., 2018, 9.

5. Spinoni, J., Naumann, G. and Vogt, J. V., Pan-European seasonal trends and recent changes of drought frequency and severity. Global Planet. Change, 2017, 148, 113-130.

6. Forzieri, G. et al., Escalating impacts of climate extremes on critical infrastructures in Europe. Global Environ. Change, 2018, 48, $97-107$.

7. Mentaschi, L., Vousdoukas, M. I., Pekel, J. F., Voukouvalas, E. and Feyen, L., Global long-term observations of coastal erosion and accretion. Sci. Rep., 2018, 8, 1-11.

8. Watts, N. et al., The lancet countdown: tracking progress on health and climate change. Lancet, 2017, 389, 1151-1164.

9. Kapur, A., Vulnerable India: a Geographical Study of Disasters, SAGE Publications, 2010; https://doi.org/10.4135/9788132105428.

10. Flatø, M., Muttarak, R. and Pelser, A., Women, weather and woes: the triangular dynamics of female-headed households, economic vulnerability and climate variability in South Africa. World Dev., $2017,90,41-62$

11. Neumayer, E. and Plümper, T., The gendered nature of natural disasters: the impact of catastrophic events on the gender gap in life expectancy, 1981-2002. Ann. Assoc. Am. Geogr., 2007, 97, 551-566.

12. Lass, W., Haas, A., Hinkel, J. and Jaeger, C., Avoiding the avoidable: Towards a European heat wave risk governance. Int. J. Disaster Risk Sci., 2011, 2, 1-14; https://doi.org/10.1007/s13753-0110001-z.

13. Mishra, M., Analyzing the dynamics of social vulnerability to climate induced natural disasters in Orissa, India. Int. J. Soc. Sci., 2015, 4, 217.

14. Chhotray, V. and Few, R., Post-disaster recovery and ongoing vulnerability: ten years after the super-cyclone of 1999 in Orissa, India. Global Environ. Change, 2012, 22, 695-702.

15. Ray-Bennett, N. S., Multiple disasters and policy responses in pre- and post-independence Orissa, India. Disasters, 2009, 33, 274-290.

16. Das, S., Economics of natural disasters in Odisha. In The Economy of Odisha, Oxford University Press, 2018, pp. 266-300; https://doi.org/10.1093/acprof:oso/9780199464784.003.0009.

17. Pal, I., Ghosh, T. and Ghosh, C., Institutional framework and administrative systems for effective disaster risk governance perspectives of 2013 cyclone Phailin in India. Int. J. Disaster Risk Reduct., 2017, 21, 350-359.

18. SEOC, Situation Report on Extremely Severe Cyclonic Storm 'FANI', State Emergency Operation Centre, Bhubaneswar, 2019.

19. Das, S., Television is more effective in bringing behavioral change: evidence from heat-wave awareness campaign in India. World Dev., 2016, 88, 107-121.

20. Ray-Bennett, N. S., Disasters, deaths and the Sendai Goal One: lessons from Odisha, India. World Dev., 2018, 103, 27-39.

21. Suar, D. and Kar, S., Social and behavioural consequences of the Orissa Supercyclone. J. Health Manage., 2005, 7, 263-275. 
22. Christian, P., Kandpal, E., Palaniswamy, N. and Rao, V., Safety nets and natural disaster mitigation: evidence from cyclone Phailin in Odisha. Climate Change, 2019.

23. Walch, C., Evacuation ahead of natural disasters: evidence from cyclone Phailin in India and typhoon Haiyan in the Philippines. Geol. Geogr. Environ., 2018, 5(1), e00051; https://doi.org/ 10.1002/geo2.51.

24. Yadav, D. K. and Barve, A., Analysis of socioeconomic vulnerability for cyclone-affected communities in coastal Odisha, India. Int. J. Disaster Risk Reduct., 2017, 22, 387-396.

25. Borgerhoff Mulder, M., Msalu, L., Caro, T. and Salerno, J., Remarkable rates of lightning strike mortality in Malawi. PLOS ONE, 2012, 7, 8-11.

26. Smith, P. J., Brown, S. and Dugar, S., Community-based early warning systems for flood risk mitigation in Nepal. Nat. Hazards Earth Syst. Sci., 2017, 17, 423-437.

27. Bradshaw, S., Fordham, M., Women, girls and disasters: a review for DFID, 2013; https://gsdrc.org/document-library/women-girlsand-disasters-a-review-for-dfid/

28. Cutter, S. L., The forgotten casualties redux: women, children, and disaster risk. Global Environ. Change, 2017, 42, 117-121.

29. Lass, W., Haas, A., Hinkel, J. and Jaeger, C., Avoiding the avoidable: towards a European heat waves risk governance. Int. J. Disaster Risk Sci., 2011, 2, 1-14.

30. Eklund, L. and Tellier, S., Gender and international crisis response: do we have the data, and does it matter? Disasters, 2012, 36, 589-608.

31. Ray-Bennett, N., Caste, Class and Gender in Multiple Disasters. The Experiences of Women-Headed Household's in an Oriya Village, India, VDM Verlag Dr Muller Aktiengesellschaft \& Co. KG, Saarbrucken, 2009; ISBN 978363919379.

32. Ray-Bennett, N. S., The influence of caste, class and gender in surviving multiple disasters: a case study from Orissa, India. Environ. Hazards, 2009, 8, 5-22.

33. Selvi, S. and Rajapandian, S., Analysis of lightning hazards in India. Int. J. Disaster Risk Reduct., 2016, 19, 22-24.

34. TOI, Odisha registers $31 \%$ decline in number of lightning deaths. Times of India, Bhubaneswar, July 2019.

35. Singh, O. and Singh, J., Lightning fatalities over India: 19792011. Meteorol. Appl., 2015, 22, 770-778.
36. Gouda, K. C., Sahoo, S. K., Samantray, P. and Himesh, S., Simulation of extreme temperature over Odisha during May 2015. Weather Climate Extrem., 2017, 17, 17-28.

37. Singha, M., Odisha faces highest lightning strikes in country, but sees lowest deaths. Times of India, Bhubaneswar, September 2019.

38. Barik, S., Odisha to plant palms to arrest lightning bolts. Hindu, Bhubaneswar, May 2018.

39. Nageswararao, M. M., Sinha, P., Mohanty, U. C. and Mishra, S., Occurrence of more heat waves over the Central East Coast of India in the recent warming era. Pure Appl. Geophys., 2019, 177(2), 1143-1155; https://doi.org/10.1007/s00024-019-02304-2.

40. Medina-Ramón, M. and Schwartz, J., Temperature, temperature extremes, and mortality: a study of acclimatisation and effect modification in 50 US cities. Occup. Environ. Med., 2007, 64, $827-833$.

41. Joe, L. et al., Mortality during a large-scale heat wave by place, demographic group, internal and external causes of death, and building climate zone. Int. J. Environ. Res. Public Health, 2016, 13(3), 299; https://doi.org/10.3390/ijerph13030299.

42. Mora, C., Counsell, C. W. W., Bielecki, C. R. and Louis, L. V., Twenty-seven ways a heat wave can kill you: deadly heat in the era of climate change. Circ. Cardiovasc. Qual. Outcomes, 2017, 10.

43. Ingole, V. et al., Socio-environmental factors associated with heat and cold-related mortality in Vadu HDSS, western India: a population-based case-crossover study. Int. J. Biometeorol., 2017, 61, 1797-1804.

44. Murari, K. K. and Ghosh, S., Future heat wave projections and impacts. In Climate Change Signals and Response, Springer, Singapore, 2019, pp. 91-107.

45. Jahn, M., Economics of extreme weather events: terminology and regional impact models. Weather Climate Extrem., 2015, 10, 2939.

Received 14 October 2020; revised accepted 25 March 2021

doi: $10.18520 / \mathrm{cs} / \mathrm{v} 120 / \mathrm{i} 11 / 1721-1727$ 